\title{
Angle resolved characterization of nanostructured and conventionally textured silicon solar cells
}

Davidsen, Rasmus Schmidt; Ormstrup, Jeppe; Ommen, Martin Lind; Larsen, Peter Emil; Schmidt, Michael Stenbæk; Boisen, Anja; Nordseth, Ørnulf; Hansen, Ole

Published in:

Solar Energy Materials \& Solar Cells

Link to article, DOI:

10.1016/j.solmat.2015.04.001

Publication date:

2015

Document Version

Peer reviewed version

Link back to DTU Orbit

Citation (APA):

Davidsen, R. S., Ormstrup, J., Ommen, M. L., Larsen, P. E., Schmidt, M. S., Boisen, A., Nordseth, Ø., \& Hansen, O. (2015). Angle resolved characterization of nanostructured and conventionally textured silicon solar cells. Solar Energy Materials \& Solar Cells, 140, 134-140. https://doi.org/10.1016/j.solmat.2015.04.001

\section{General rights}

Copyright and moral rights for the publications made accessible in the public portal are retained by the authors and/or other copyright owners and it is a condition of accessing publications that users recognise and abide by the legal requirements associated with these rights.

- Users may download and print one copy of any publication from the public portal for the purpose of private study or research.

- You may not further distribute the material or use it for any profit-making activity or commercial gain

- You may freely distribute the URL identifying the publication in the public portal 


\title{
Angle resolved characterization of nanostructured and conventionally textured silicon solar cells
}

\author{
Rasmus Schmidt Davidsen ${ }^{\mathrm{a}, *}$, Jeppe Ormstrup ${ }^{\mathrm{a}}$, Martin Lind Ommen ${ }^{\mathrm{a}}$, Peter \\ Emil Larsen ${ }^{\mathrm{a}}$, Michael Stenbæk Schmidt ${ }^{\mathrm{a}}$, Anja Boisen ${ }^{\mathrm{a}}$, Ørnulf Nordseth ${ }^{\mathrm{c}}$, \\ Ole Hansen ${ }^{\mathrm{a}, \mathrm{b}}$ \\ ${ }^{a}$ Department of Micro- and Nanotechnology, Technical University of Denmark (DTU) \\ ${ }^{b}$ Danish National Research Foundation's Center for Individual Nanoparticle Functionality \\ (CINF), Technical University of Denmark, DK-2800 Kgs.Lyngby, Denmark \\ ${ }^{c}$ IFE, Institute for Energy Technology, Norway
}

\begin{abstract}
We report angle resolved characterization of nanostructured and conventionally textured silicon solar cells. The nanostructured solar cells are realized through a single step, mask-less, scalable reactive ion etching (RIE) texturing of the surface. Photovoltaic properties including short circuit current, open circuit voltage, fill factor (FF) and power conversion efficiency are each measured as function of the relative incident angle between the solar cell and the light source. The relative incident angle is varied from 0 to 90 degrees in steps of 10 degrees in orthogonal axes, such that each solar cell is characterized at 100 different angle combinations. The angle resolved photovoltaic properties are summarized in terms of the average, angle-dependent electrical power output normalized to the power output at normal incidence and differently textured cells on different silicon substrates are compared in terms of angle resolved performance. The results show a $3 \%$ point improvement in average electrical power output normalized with respect to normal incidence power output of RIE textured, multi crystalline Si cells compared to conventional multi crystalline Si cells and above $1 \%$ point improvement of RIE textured mono crystalline Si cells compared to conventional mono crystalline Si cells.
\end{abstract}

*Corresponding Author, email: rasda@nanotech.dtu.dk, Ørsteds Plads building 345 East, 2800 Lyngby, Denmark, Tel.: +45 45256397 
Keywords: black silicon, reactive ion etching, incident angle, reflectance, angle-resolved characterization

\section{Introduction}

Solar cells are generally characterized at standard test conditions i.e. at light intensity of $1000 \mathrm{~W} / \mathrm{m}^{2}, \mathrm{AM} 1.5 \mathrm{G}{ }^{1}$ illumination, temperature of $25^{\circ} \mathrm{C}$ and light at normal incidence, which means that the incident simulated sunlight 5 beam is directed at an angle of $90^{\circ}$ relative to the solar cell plane. However these conditions only represent a very limited fraction of actual, realistic operating conditions for solar cells and panels. The temperature of the cell and the intensity and incidence angle of the sunlight indeed vary between different geographical locations and throughout the duration of a day and a year. Furthermore solar cells are subject to diffuse light whenever clouds, dust or any obstacles in the air scatter the sunlight before it reaches the solar cell surface. For this reason there is a need for a more detailed characterization scheme for solar cells, which takes these variations into account. In particular when considering alternative solar cell types employing features such as nanoscale texturing

15 of the solar cell surface, the angle-resolved and low light performance becomes more important, since nanoscale texturing has been shown [1] [2] to yield superior reflectance properties over a broad range of incident angles compared to conventionally textured solar cells.

We use Black Silicon (BS) 4] [5] nanostructuring to achieve low reflectance due to the resulting graded refractive index at the Si-air interface. Low broadband reflectance at different incident angles has been reported for moth-eye surfaces [6] [7] and different types of black silicon [8] fabricated by means of various methods. This work focuses on black Si fabricated by maskless reactive ion etching (RIE). Repo et al. 9] achieved a power conversion efficiency of $18.7 \%$ on $400 \mu \mathrm{m}$ ${ }_{25}$ thick float-zone Si using cryogenic deep RIE as texturing and plasma assisted

\footnotetext{
${ }^{1} \mathrm{AM} 1.5 \mathrm{G}=$ Air Mass of 1.5 Global
} 
atomic layer deposition (ALD) of $\mathrm{Al}_{2} \mathrm{O}_{3}$ for a passivated emitter rear locally diffused (PERL) cell. Oh et al. 3] achieved a power conversion efficiency of $18.2 \%$ on $300 \mu \mathrm{m}$ thick float-zone Si by combining a metal-assisted wet etching black silicon process for texturing, TMAH damage removal etch and double-sided thermal $\mathrm{SiO}_{2}$ passivation. Yoo et al. [10] used industry grade Czochralski Si and RIE texturing and achieved a power conversion efficiency of $16.7 \%$. Several groups have reported improved light absorption over a broad range of incident angles of nanostructured [11] [12, [13, [14] and differently textured Si including the PERL-cell [15] [16]. Considering these reported improved angle-dependent optical properties of nanostructured Si and the correlation between overcast sky (diffuse light) conditions and relative incident angle of the sunlight [17, 18, 19] [20], the relationship between nanostructured Si solar cells and angle-dependent photovoltaic performance is of utmost interest with respect to optimization of solar cell performance under realistic operating conditions such as diffuse light.

40 Lee et al. 21] show improved average power conversion efficiency as function of incident angle of nanostructured thin film Si solar cells in comparison with "conventional" thin film Si cells with single and double anti-reflective (AR) coating. However, a detailed study of the angle-dependent photovoltaic performance of nanostructured, large-area Si solar cells based on industrial type Si substrates in

45 direct comparison with conventionally textured Si solar cells, has not yet been reported.

This work presents an angle-resolved characterization approach of solar cells in general and measured angle-resolved photovoltaic properties of nanostructured Si solar cells in comparison with conventionally textured Si solar cells.

\section{Approach}

The maskless RIE process presented in this work is applied as the texturing step in the following solar cell fabrication process:

- Saw damage removal by etching in $30 \% \mathrm{KOH}$ at $75^{\circ} \mathrm{C}$ for 2 minutes and subsequent cleaning in $20 \% \mathrm{HCl}$ at room temperature for 5 minutes and 
rinsing in deionized water.

- Texturing using maskless RIE at room temperature in a $\mathrm{O}_{2}$ and $\mathrm{SF}_{6}$ plasma with a gas flow ratio of $\mathrm{O}_{2}: \mathrm{SF}_{6} \approx 1: 1$, chamber pressure of 28 mTorr, $13.56 \mathrm{MHz}$ radio-frequency platen power of $30 \mathrm{~W}$ using a STS RIE system.

- Emitter formation using a tube furnace from Tempress Systems with liquid $\mathrm{POCl}_{3}$ as dopant source and $\mathrm{N}_{2}$ as carrier gas at a temperature of $840^{\circ} \mathrm{C}$ and atmospheric pressure for $50 \mathrm{~min}$ in $\mathrm{O}_{2}$ ambient, followed by removal of phosphor-silicate glass (PSG) in $5 \%$ hydrofluoric acid (HF).

- Plasma enhanced chemical vapour deposition (PECVD) of $60 \mathrm{~nm}$ hydrogenated amorphous silicon nitride $\left(\mathrm{SiN}_{x}: \mathrm{H}\right)$ anti-reflective coating at $400^{\circ} \mathrm{C}$ using a PlasmaLab System133 from Oxford Instruments.

- Screen-printing of $\mathrm{Ag}$ front and $\mathrm{Al}$ rear contacts with standard Ag and Al pastes using an Ekra X5-STS screen printer, followed by co-firing of the front and rear contacts at $800^{\circ} \mathrm{C}$ using an RTC Model LA-309 belt

70 furnace.

- Edge isolation by laser ablation using a J-1030-515-343 FS System from Oxford Lasers Ltd.

The starting substrates were $156 \times 156 \mathrm{~mm}^{2}$ p-type, CZ mono-, multi- and quasimono-crystalline Si wafers with a thickness of $200 \mu \mathrm{m}$ and a resistivity of 1-3 Ohm cm.

\section{Characterization}

Normal incidence reflectance measurements of the RIE-textured mono-, multi and quasi-mono Si surfaces were performed using a broadband lightsource (Mikropack DH-2000), an integrating sphere (Mikropack ISP-30-6-R), and a spectrometer 80 (Ocean Optics QE65000, 280-1000 nm). The reference solar spectral irradiance 
for AM 1.5 was used to calculate the weighted average reflectance in the wavelength range from 280-1000 $\mathrm{nm}$. The angle-dependent optical reflectance was measured with monochromatic light from $350 \mathrm{~nm}$ to $1200 \mathrm{~nm}$ using an APEX monochromator illuminator with an Oriel Cornerstone 260 1/4m monochromator. A quartz crystal achromatic depolarizer from Thorlabs was used in the beam path to randomize the partly polarized light from the monochromator. The sample was inserted inside a $150 \mathrm{~mm}$ integrating sphere with a center mount configuration and rotated to any desired angle of incidence.

$\mathrm{I}-\mathrm{V}$ curves and photovoltaic properties including short-circuit current, $\mathrm{I}_{S C}$, open-circuit voltage, $\mathrm{V}_{O C}$, fill factor, $\mathrm{FF}$, and electrical output power, $P_{e l}$, were measured on complete cells under 1 sun illumination $\left(1000 \mathrm{~W} / \mathrm{m}^{2}\right.$, AM1.5G) using a Newport Oriel 92190 large-area Xe light source and a Keithley 2651A high-power source meter.

In order to characterize the solar cell performance at varying incident angles, ${ }_{95} \mathrm{I}-\mathrm{V}$ curves were measured on differently textured Si solar cells mounted and contacted on a stage, which prior to each I-V curve measurement was tilted to a position given by two angles, $\theta$ and $\phi$, around two orthogonal axes: $\theta$ is the tilt of the cell plane with respect to the original, horizontal $\mathrm{x}$-axis and $\phi$ is the tilt of the cell plane with respect to the tilted y-axis. The light source was fixed during all measurements. The measurement setup including the two angles $\theta$ and $\phi$ is sketched in Fig. 4. The incidence angle was varied using two JVL QuickStep stepping motors connected to the solar cell stage. Each angle was randomly varied in steps of $10^{\circ}$ in the range $0-90^{\circ}$ unless otherwise specified. At each angle combination, $(\theta, \phi)$, the I-V curve was measured under 1 sun and the result collected using LabView, such that a total of $100 \mathrm{I}-\mathrm{V}$ curves were measured for each cell. The measured I-V curves were then analyzed in order to determine $\mathrm{I}_{S C}, \mathrm{~V}_{O C}, \mathrm{FF}$ and $P_{e l}$ at each angle combination, $(\theta, \phi)$, using SciLab. Finally the angle-resolved photovoltaic properties were plotted and the average electrical power output normalized to the normal incidence power output was calculated in order to compare the angle-dependency of different cells. A LEO 1550 Scanning Electron Microscope (SEM) was used to characterize the 
nanostructured surface topology.

\section{Results}

An example of the nanostructured surfaces realized by maskless RIE in this work is seen in Figure 1.

The nanostructures seen in Figure 1 are conical-like hillocks randomly distributed across the entire solar cell surface. The nanostructures are on average $300-400 \mathrm{~nm}$ tall with an area density of $\sim 100 \mu \mathrm{m}^{-2}$. The topology is shown with and without $\sim 60 \mathrm{~nm} \mathrm{PECVD} \operatorname{SiN}_{x}: \mathrm{H}$ in Fig 1. It is seen from Figure 1(a) that

the $\mathrm{SiN}_{x}: \mathrm{H}$ AR-coating does not change the RIE-textured topology significantly, but makes the nanostructure edges slightly more round and smooth.

Figure 2 shows total weighted average reflectance of RIE-textured Si below $1.1 \%$ for all three crystalline grades of $\mathrm{Si}$, which is a clear improvement compared to $\mathrm{KOH}-$ and acidic-textured $\mathrm{Si}$ used in standard industrial Si solar cells. With anti-reflective coating $\mathrm{KOH}$-textured Si has reflectance of $2 \%$ 22], while acidic-textured multi-crystalline $\mathrm{Si}$ has reflectance of $8 \%$ 23]. It is seen that the average reflectance is unaffected by the $\sim 60 \mathrm{~nm}$ PECVD $\mathrm{SiN}_{x}: \mathrm{H}$ AR-coating. The results furthermore show negligible increase in reflectance after emitter diffusion. The RIE-textured Si shows $\sim 0.1 \%$ minimum reflectance independent of crystalline grade. The power conversion efficiencies at normal incidence of the fabricated solar cells are summarized in Table 1 . Table 1 shows that the RIE-textured cells have lower power conversion efficiency than the conventionally textured cells primarily due to lower short-circuit current, but also reduced open-circuit voltage. Based on IQE-measurements and LASSIE $2^{2}$ analysis, the current and voltage losses were explained by increased emitter and surface recombination 24]. For the cells fabricated in this work, the texturing and thus reflectance was not fully optimized. Since the RIE-texturing has been further optimized after these cells were fabricated, with a resulting weighted average

\footnotetext{
${ }^{2}$ Loss Analysis of Silicon Solar cells by IQE Evaluation
} 
reflectance below $1 \%$, it is expected that the power conversion efficiency will be increased in future studies. In addition, optimized post RIE processing may reduce emitter recombination.

Figure 3 shows the total weighted (AM1.5) average reflectance as function of incident angle for standard, KOH-textured (squares) and RIE-textured (triangles) mono-crystalline Si substrates. The reflectance was measured using an integrating sphere with one axis angle variation of the incident optical fiber relative to the Si substrate. The results in Figure 3 show that the reflectance of RIE-textured Si is significantly below that of $\mathrm{KOH}$-textured $\mathrm{Si}$ at all incident angles below $70^{\circ}$. Furthermore the reflectance of $\mathrm{KOH}$-textured Si increases more with incident angle up to $50^{\circ}$ than the reflectance of RIE-textured Si.

150 For angles above $50^{\circ}$ the reflectance of RIE-textured Si increases more with incident angle than that of $\mathrm{KOH}$-textured Si. This result shows the potential for improved solar cell performance using RIE-texturing at non-ideal incident angles.

There are two reasons for measuring parameters such as $\mathrm{I}_{S C}, \mathrm{~V}_{O C}, \mathrm{FF}$ and power output as function of two different incident angles and plotting the result in a 2-D plot such as in Figure 4 First of all, the intention of this work is to demonstrate a new and different method for characterization of solar cells in general. By measuring IV-data as function of two orthogonal incident angles in combination, realistic angle-resolved scenarios such as diffuse light conditions can be investigated in more detail. Secondly, this method allows for a quantification of any asymmetric features of the solar cell with respect to incident angle of the light, whether on the surface or inside the cell. Examples of this are isotropic compared anisotropic texturing methods and light trapping properties. We acknowledge that the asymmetric behaviour seen in Figure 4 is not significant considering the uncertainties of the measurement. Thus, the choice of a 2-D plot in this case is a demonstration of the method and its capabilities, rather than a thorough analysis of asymmetric angle-resolved behaviour.

Figure 4 shows that $\mathrm{V}_{O C}$ and $\mathrm{FF}$ do not change significantly for angles below $80^{\circ}$. $\mathrm{I}_{S C}$ and consequently $P_{e l}$ decrease with increasing incident angle. This 
170 is expected since the optical input power, $P$, on the solar cell decreases with cosine to the incident angle, since the effective illuminated area decreases with cosine to the angle according to Eq. 1. In the experimental setup the optical power incident on the cell for angle variation $\theta$ is given by

$$
P=P(\theta)=\Phi_{0} W^{2} \cos (\theta)=P_{0} \cos (\theta)
$$

under ideal conditions. Here $W$ is the edge length of the cell, $\Phi_{0}$ is the optical intensity and $P_{0}$ is the optical power incident on the cell at normal incidence. The efficiency of the cell, which may be angle dependent, is

$$
\eta(\theta)=\frac{P_{e l}(\theta)}{P(\theta)}
$$

where $P_{e l}$ is the electrical output power at optimal load conditions. Part of any angular dependence in the efficiency is due to angular dependence of the reflection coefficient, $r(\theta)$, and this dependency is made explicit, if an internal efficiency $\eta_{\text {int }}$ is defined such that

$$
\eta(\theta)=\eta_{\text {int }}(\theta)[1-r(\theta)]
$$

The internal efficiency, $\eta_{\text {int }}(\theta)$, could be angle dependent due to increased photon path length within the silicon for increasing $\theta$ and consequently increasing collection probability. Investigation of this effect is beyond the scope of this work.

185 These efficiencies are the physically relevant parameters for the cell. For convenient presentation of the raw measurement data, an artificial apparent efficiency $\eta_{\text {app }}$ may be defined as

$$
\eta_{a p p}(\theta)=\frac{P_{e l}(\theta)}{P_{0}}=\eta(\theta) \cos (\theta)
$$

and from the rightmost expression in Eq. 4 it is seen that if the cell has an efficiency without angular dependency, then the apparent efficiency has a cosine angular dependency. The measured apparent efficiency for the RIE-textured mono-crystalline Si cell is plotted in Figure 5 , in the plot the expected apparent efficiency given in Eq. 4 assuming a constant $\eta$ is also shown for comparison. For 
simplicity the results are only shown with angle variation in one axis. Figure 5 shows that the experimentally measured apparent efficiency is higher than expected for incident angles below $60^{\circ}$. This may in part be explained by divergence of the light source, which changes the actual optical input power according to Eq. 5 .

$$
P(\theta)=\Phi_{0} W^{2} \frac{\cos (\theta)}{1-\left(\frac{W}{2 L} \sin (\theta)\right)^{2}}
$$

where $L$ is a characteristic length parameter of the divergence. Note that the term $1-\left(\frac{W}{2 L} \sin (\theta)\right)^{2}$ is a possible correction term related purely to the measurement setup. Eq. 5 shows that divergence of the light source accounts for measured apparent efficiency values higher than expected. However, efficiency values lower than expected, as seen for incident angles higher than $60^{\circ}$ in Fig. 5 can not be explained by divergence of the light source and are most probably a result of increased reflectance at higher incident angles. $P_{e l}$ decreases according to Eq. 3 when the reflected part of the optical input power, $r(\theta)$, increases with incident angle as shown in Fig. 3.

In order to evaluate the actual angle dependency of the differently textured solar cells, the measured electrical power output was normalized to the electrical power output at normal incidence, $(0,0)$. Figure 6 shows the angle-dependent normalized power output for the RIE- and conventionally textured mono- and multi-crystalline Si cell, respectively, for comparison. Figure 6 shows that the RIE-textured mono- and multi-crystalline cells in general have slightly higher angle-resolved efficiency normalized to the efficiency at normal incidence compared to the conventionally textured cells. For certain incidence angles above $60^{\circ}$ the conventionally textured mono-crystalline cell shows slightly higher normalized efficiency compared to the RIE-textured. Figure6 also shows an asymmetric behaviour with respect to the two angles, $\theta$ and $\phi$. The asymmetry occurs for both RIE- and conventionally textured cells, which indicates that the asymmetric behaviour is partly due to imperfections in the measurement setup. 220 However, it is seen that the asymmetry is slightly larger for the conventional cells for most angles. This might be explained by the different rotational sym- 
metries for the differently textured topologies: The black silicon cell - due to the random nature of the surface nanostructures should only be affected by the polar angle of the incident light, whereas the azimuthal angle should not matter. The same may not be true for $\mathrm{KOH}$ textured cells, where the pyramids may be of random size, but they all share a fourfold symmetry in the azimuthal angle; it follows that some degree of variation with the azimuthal angle may be present for $\mathrm{KOH}$ cells.

The asymmetric behaviour may also be due to the front metallization, which reduces the symmetry to twofold or lower.

Yet, the observed asymmetry is too small compared to the uncertainties of this measurement to conclude whether the asymmetry is actually due to topology differences or measurement inaccuracy. Angle-resolved properties similar to the results in Figure 4 were measured for nanostructured mono-, multi- and quasi-mono-crystalline Si cells and conventionally textured mono- and multi-crystalline Si cells for comparison. Since texturing of quasi-mono-crystalline $\mathrm{Si}$ cells is not yet fully established or standardized, no such cell was produced. Based on the measured angle-resolved electrical power output, the average normalized electrical power output, $\Psi_{\mathrm{av}}$, relative to the power output at normal incidence can be compared for each of the differently textured cells. $\Psi_{\mathrm{av}}$ is given by the expression in Eq. 6 and the resulting values of average relative power output are shown in Table 2 and Figure 7.

$$
\Psi_{\mathrm{av}}=\frac{1}{N} \sum_{\theta=0}^{90} \sum_{\phi=0}^{90} \frac{P_{e l}(\theta, \phi)}{P_{e l}(0,0)}
$$

In Eq. 6 $N$ denotes the total number of efficiency values which is being averaged over. In the case of averaging over incident angles in the range of $0-90^{\circ}$ in steps of $10^{\circ}$ in both axes, $N=100 . P_{e l}$ denotes the measured electrical power output of the cell. 
The results in Figure 7 and Table 2 show that the average normalized power broad range of incident angles representing e.g. angle variation during daily and yearly operation of solar cells and panels. Furthermore, and perhaps more importantly, such less angle-dependent behaviour as seen on Figure 7 represents improved performance under diffuse light conditions for nanostructured solar 275

output is also higher for the RIE-textured cells compared to the reference cells in the incident angle range of $0-40^{\circ}$. Furthermore the difference between the RIE-textured and the reference cells is even more significant in this smaller range of angles closer to normal incidence. This angular range is arguably more interesting than $0-90^{\circ}$ due to e.g. higher sunlight intensity close to normal incidence and the effective restriction of incident angles of light reaching the solar cells due to refraction and reflection of light from the protective glass covering solar cells in practice. In order to account for these differences, it is needed to do a complete weighing of the different incident angles and angle ranges. Such analysis is out of the scope of this work, but the results indicate the need for a more detailed analysis.

\section{Discussion}

The results in Table 1 show that the RIE-textured cells have lower power conversion efficiency at normal incidence due to increased surface recombination of the RIE-textured cells [24].

However, the average electrical power output normalized to the power output at normal incidence shown in Figure 7 is higher for the RIE-textured cells compared to the conventionally textured cells; both for mono- and multi-crystalline Si. This indicates a less angle-dependent power output of such nanostructured Si solar cells compared with conventionally textured Si solar cells in general. Less angle-dependent power output implies potentially higher power output over a cells compared with conventionally textured solar cells. Since diffuse light is a realistic and important operating condition, which affects the performance of commercial solar cells and panels significantly, this result shows the potential 
of nanoscale texturing, such as maskless RIE-texturing, as a way of improving the overall performance of Si solar cells by enhancing the diffuse and low light performance and thus create a more stable and angle-independent solar cell performance.

\section{Conclusion}

A method for angle-resolved characterization of solar cells in general and measured angle-dependent photovoltaic properties of nanostructured and conventionally textured mono, multi and quasi-mono crystalline Si solar cells, respectively, have been presented. Compared with conventionally textured cells the nanostructured solar cells have lower power production over a broad range of incident angles due to lower power conversion efficiency in general. However, the RIE-textured multi-crystalline Si cells show a $3 \%$ point improvement in average normalized angle resolved power output compared to conventionally textured and the RIE-textured mono-crystalline Si cells show above $1 \%$ point improvement compared to conventionally textured.

\section{Acknowledgements}

Center for Individual Nanoparticle Functionality (CINF) is sponsored by The Danish National Research Foundation (DNRF 54).

\section{References}

[1] Liu, X., Coxon, P.R., Peters, M., Hoex, B., Cole, J.M., Fray, D.J., "Black Silicon: Fabrication methods, properties, and solar energy applications", Review Article, Energy \& Environmental Science, Royal Society of Chemistry 7 3223-3263 (2014) DOI: 10.1039/c4ee01152j.

[2] Rahman, A., Ashraf,A., Xin, H., Tong, X., Sutter, P., Eisaman, M.D., Black, C.T., "Sub-50-nm self-assembled nanotextures for enhanced broadband antireflection in silicon solar cells", Nature Communications 6, 5963 (2015), DOI: 10.1038/ncomms6963. 
[3] Oh, J., Yuan, H.C., Branz, H., "An 18.2 \%-efficient black-silicon solar cell achieved through control of carrier recombination in nanostructures", Nature Nanotechnology 7 743-748 (2012).

[4] Her, T.H., Finlay, R.J., Wu, C., Deliwala, S., Mazur, E., "Microstructuring of silicon with femtosecond laser pulses", Appl. Phys. Lett. 73 1673-1675 (1998).

[5] Jansen, H., Deboer, M., Legtenberg, R., Elwenspoek, M., "The Black Silicon Method - a Universal Method for Determining the Parameter Setting of a Fluorine-Based Reactive Ion Etcher in Deep Silicon Trench Etching with Profile Control", Journal of Micromechanics and Microengineering 5 $115-120$ (1995).

[6] Boden, S.A., Bagnall, D.M., "Optimization of moth-eye antireflection schemes for silicon solar cells Prog. Photovolt: Res. Appl. 18195203 (2010), DOI: $10.1002 /$ pip.951.

[7] Wilson, S.J., Hutley, M.C., The Optical Properties of 'Moth Eye' Antireflection Surfaces, Optica Acta: International Journal of Optics, 29:7 9931009 (1982), DOI:10.1080/713820946.

[8] Priolo, F., Gregorkiewicz, T., Galli, M., Krauss, T.F., Silicon nanostructures for photonics and photovoltaics, Nature Nanotechnology 9 19-32 (2014) DOI: 10.1038/NNANO.2013.271.

[9] Repo, P., Benick, J., Vähänissi, V., Schön, J., von Gastrow, G., Steinhauser, B., Schubert, M.C., Hermle, M., Savin, H., "N-type black silicon solar cells", SiliconPV, Energy Procedia 38 866-871 (2013).

[10] Yoo, J., "Reactive ion etching (RIE) technique for application in crystalline silicon solar cells", Solar Energy 84 730-734 (2010).

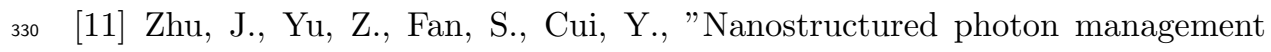
for high performance solar cells", Materials Science and Engineering R 70 330-340 (2010). 
[12] Nguyen, K.N., Abi-Saab, D., Basset, P., Richalot, E., Marty, F., Angelescu, D., Leprince-Wang, Y., Bourouina, T., "Black silicon with sub-percent reflectivity: Influence of the 3D texturization geometry", Solid-State Sensors, Actuators and Microsystems Conference (Transducers), 16th International Transducers 11 354-357 (2011).

[13] Kelzenberg, M.D., Boettcher, S.W., Petykiewicz, J.A., Turner-Evans, D.B., Putnam, M.C., Warren, E.L., Spurgeon, J.M., Briggs, R.M., Lewis, N.S., Atwater, H.A., "Enhanced absorption and carrier collection in Si wire arrays for photovoltaic applications", Nature Materials 9239244 (2010), DOI: 10.1038/NMAT2635.

[14] Huang, Y-F., Chattopadhyay, S., Jen, Y-J., Peng, C-Y., Liu, T-A., Hsu, Y-K., Pan, C-L., Lo, H-C., Hsu, C-H., Chang, Y-H., Lee, C-S., Chen, K-H., Chen, L-C., "Improved broadband and quasiomnidirectional anti-reflection properties with biomimetic silicon nanostructures", Nature Nanotechnology 2770 - 774 (2007).

[15] Parretta, A., Sarno, A., Tortora, P., Yakubu, H., Maddalena, P., Zhao, J., Wang, A., "Angle-dependent reflectance measurements on photovoltaic materials and solar cells", Optics Communications 172 139-151 (1999).

[16] Zhao, J., Wang, A., Green, M.A., "24.5 \% Efficiency Silicon PERT Cells on MCZ Substrates and 24.7 \% Efficiency PERL Cells on FZ Substrates", Progress in Photovoltaics: Research and Applications 7 471-474 (1999).

[17] King, D.L., Kratochvil, J.A., Boyson, W.E., "Measuring Solar Spectral and Angle-of-Incidence Effects on Photovoltaic Modules and Solar Irradiance Sensors", 26th IEEE Photovoltaic Specialists Conference 1113-1116 (1997).

[18] Anderson, M.C., "Stand Structure and Light Penetration II. A Theoretical Analysis", Journal of Applied Ecology 3 No.1 41-54 (1966).

[19] Perez, R., Ineichen, P., Seals, R., Michalsky, J., Stewart, R., "Modeling 
Daylight Availability and Irradiance Components from Direct and Global Irradiance", Solar Energy 44 No.5 271-289 (1990).

[20] Mialhe, P., "The solar cell output power dependence on the angle of incident radiation", Renewable Energy 1 No.3/4 519-521 (1991).

[21] Song, Y.M., Yu, J.S., Lee, Y.T., "Antireflective submicrometer gratings on thin-film silicon solar cells for light-absorption enhancement", Optics Letter 35 No.3 276-278 (2010).

[22] Zhao, L., Zuo, Y.H., Zhou, C.L., Li, H.L., Diao, H.W., Wang, W.J., "Theoretical investigation on the absorption enhancement of the crystalline silicon solar cells by pyramid texture coated with SiNx:H layer", Solar Energy $\mathbf{8 5}$ $370 \quad 530-537(2011)$.

[23] Macdonald, D., Cuevas, A., Kerr, M., Samundsett, C., Ruby, D., Winderbaum, S., Leo, A., "Texturing Industrial Multicrystalline Silicon Solar Cells", Solar Energy 76 No.1 277-283 (2004)

[24] Davidsen, R.S., Nordseth, Ø., Boisen, A., Schmidt, M.S., Hansen, O., 375 "Plasma texturing on large-area industrial grade CZ silicon solar cells", 28th EU PVSEC Conference Proceedings (2013). 


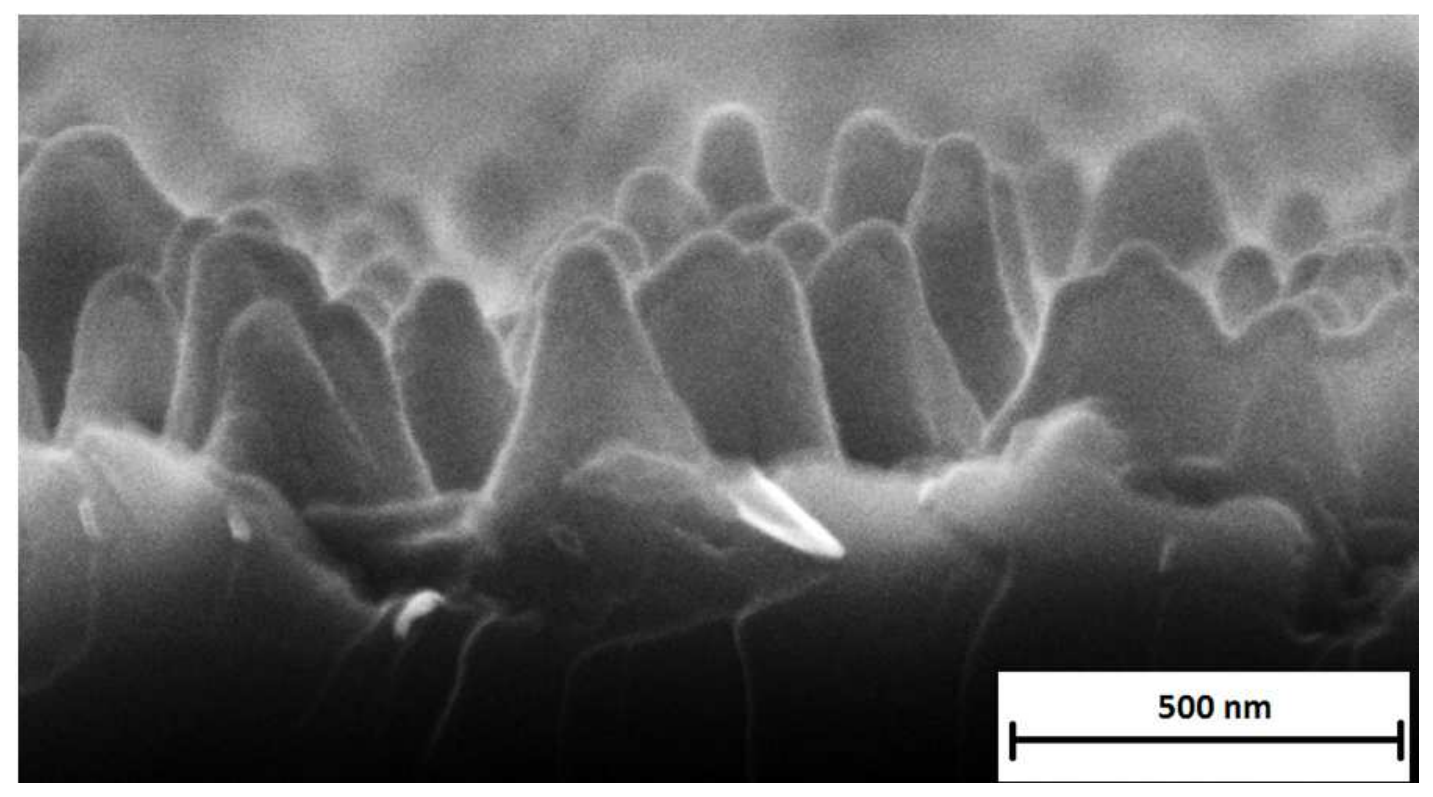

(a)

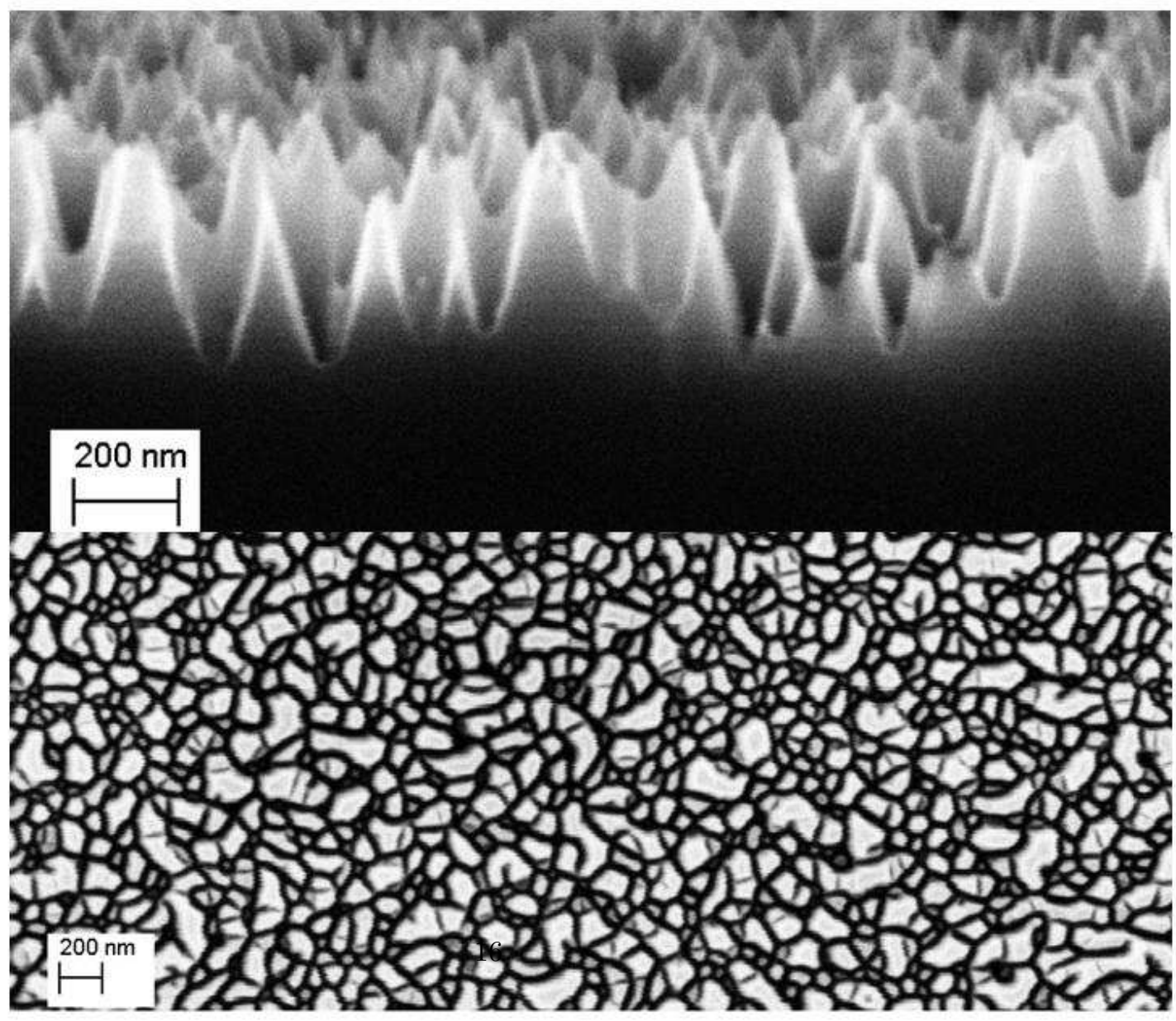

(b)

Figure 1: SEM-image at $45^{\circ}$ (a,b,top) and $0^{\circ}$ (b,bottom) tilt of the RIE-textured Si surface with (a) and without (b) $\sim 60 \mathrm{~nm} \mathrm{PECVD} \mathrm{SiN}_{x}: \mathrm{H}$ AR-coating, respectively. 


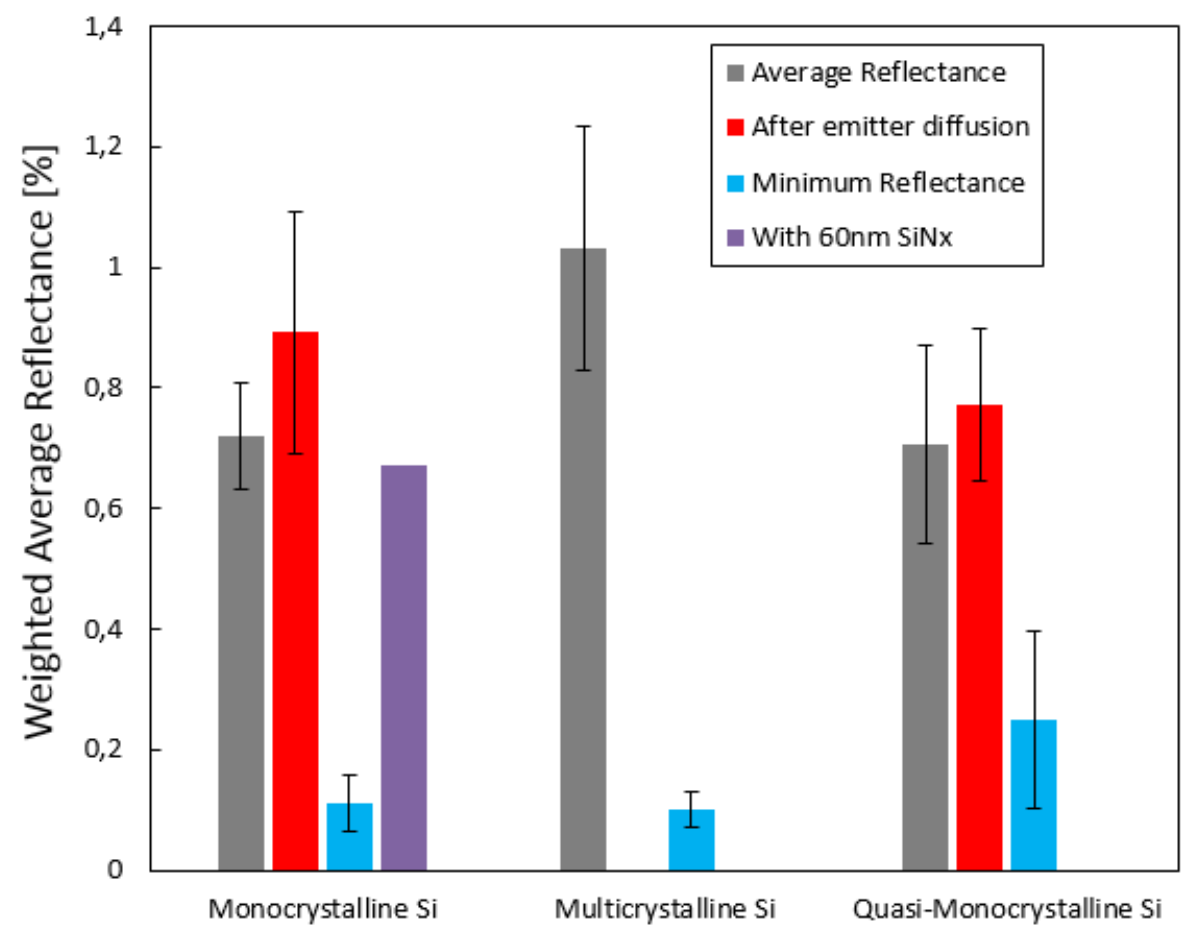

Figure 2: Total weighted (AM1.5) average reflectance before and after emitter diffusion as well as the minimum reflectance of mono-, multi- and quasi-mono Si surfaces, respectively. The average reflectance of RIE-textured mono-crystalline Si with $\sim 60 \mathrm{~nm} \mathrm{PECVD} \mathrm{SiN}_{x}: \mathrm{H}$ AR-coating is also shown. 


\begin{tabular}{lrrrr}
\hline Normal Incidence & & & & \\
\hline Cell & Efficiency $[\%]$ & $\mathrm{J}_{S C}\left[\mathrm{~mA} / \mathrm{cm}^{2}\right]$ & $\mathrm{V}_{O C}[\mathrm{mV}]$ & $\mathrm{FF}$ \\
\hline Conventional Mono & 17.8 & 36.8 & 619 & 0.78 \\
Conventional Multi & 16.5 & 34.4 & 619 & 0.77 \\
RIE Mono & 16.5 & 35.2 & 609 & 0.78 \\
RIE Multi & 14.5 & 31.7 & 592 & 0.77 \\
RIE Quasi-Mono & 13.0 & 30.0 & 575 & 0.75 \\
\hline
\end{tabular}

Table 1: Power conversion efficiency, short-circuit current, open-circuit voltage and fill factor at normal incidence of conventionally and RIE-textured mono-, multi- and quasi-monocrystalline Si cells, respectively.

\begin{tabular}{lrr}
\hline$\Psi_{\mathrm{av}}[\%],[\theta ; \phi]$ & {$\left[0-90^{\circ} ; 0-90^{\circ}\right]$} & {$\left[0-40^{\circ} ; 0-40^{\circ}\right]$} \\
\hline RIE Mono & 30.44 & 75.15 \\
RIE Multi & 31.13 & 75.69 \\
RIE Quasi-Mono & 32.16 & 76.81 \\
Conventional Mono & 29.22 & 70.39 \\
Conventional Multi & 28.18 & 72.62 \\
\hline
\end{tabular}

Table 2: Average normalized electrical power output relative to the power output at normal incidence, averaged over a range of incident angles from 0 to $90^{\circ}$ and 0 to $40^{\circ}$, respectively, in two orthogonal axis for conventional and RIE-textured mono-, multi- and quasi-monocrystalline Si solar cells, respectively. 


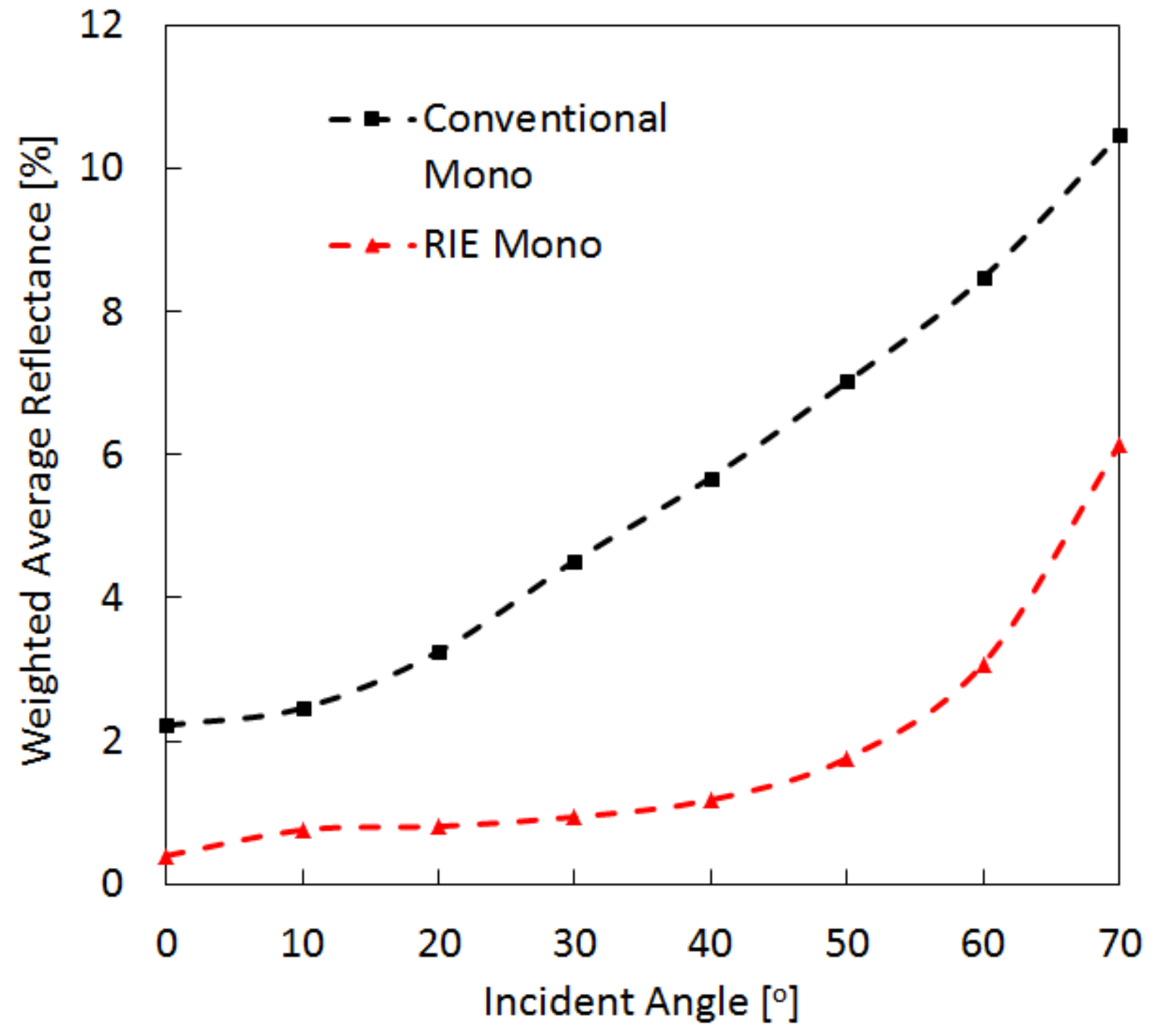

Figure 3: Incident angle dependent total weighted average reflectance of KOH-textured (squares) and RIE-textured (triangles) mono-crystalline Si substrates 


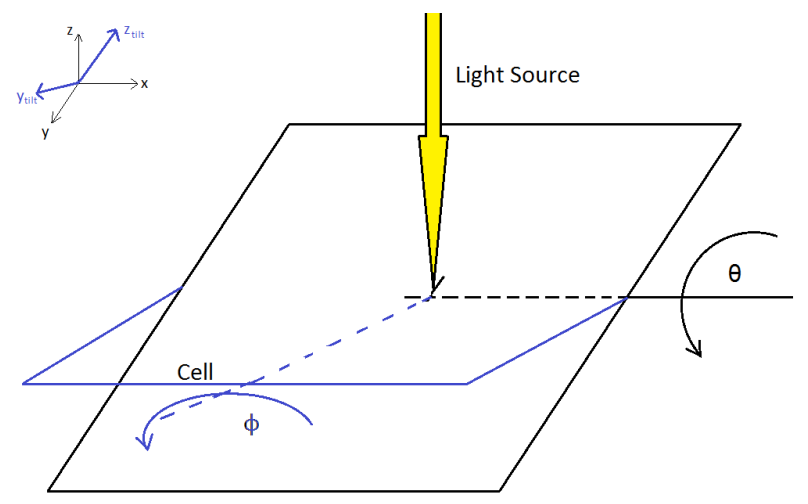

RIE-textured

Mono-crystalline Si

$V_{-}$oc $[M]$

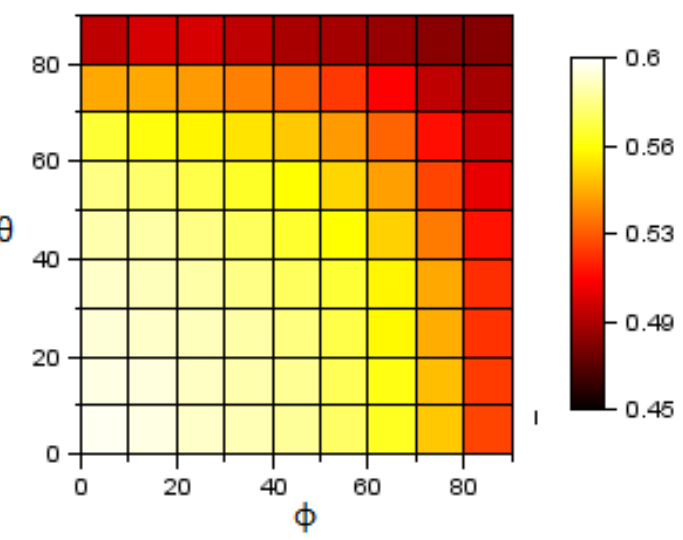

I_sc [A]

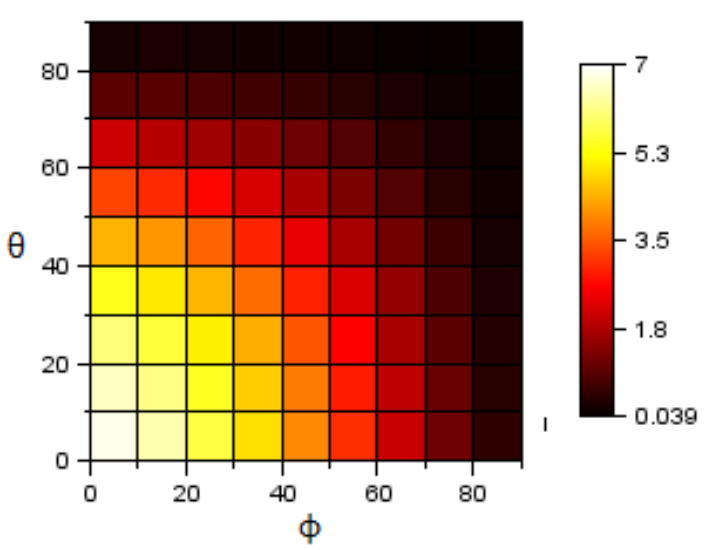

FF

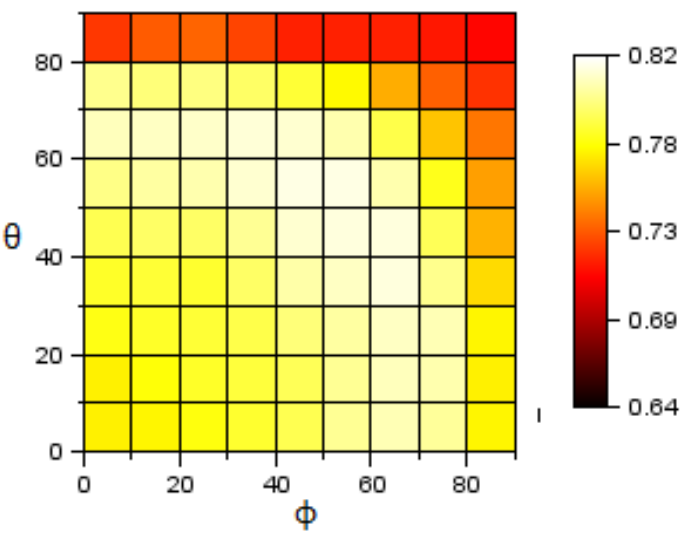

Apparent Power Conversion Efficiency [\%]

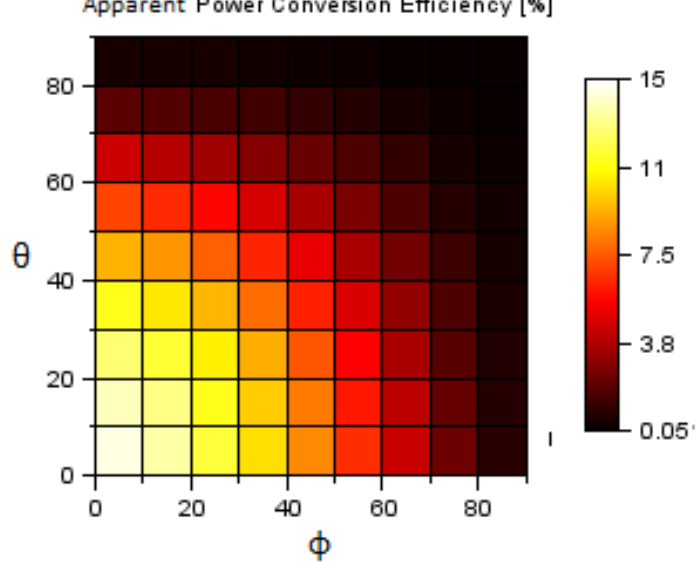

Figure 4: Angle-resolved measurement including short-circuit current, open-circuit voltage, fill factor and power conversion efficiency. The result is for a RIE-textured mono-crystalline Si solar cell. A sketch of the measurement and coordinate system is seen in the top of the figure. The angles, $\theta$ and $\phi$ are indicated. 


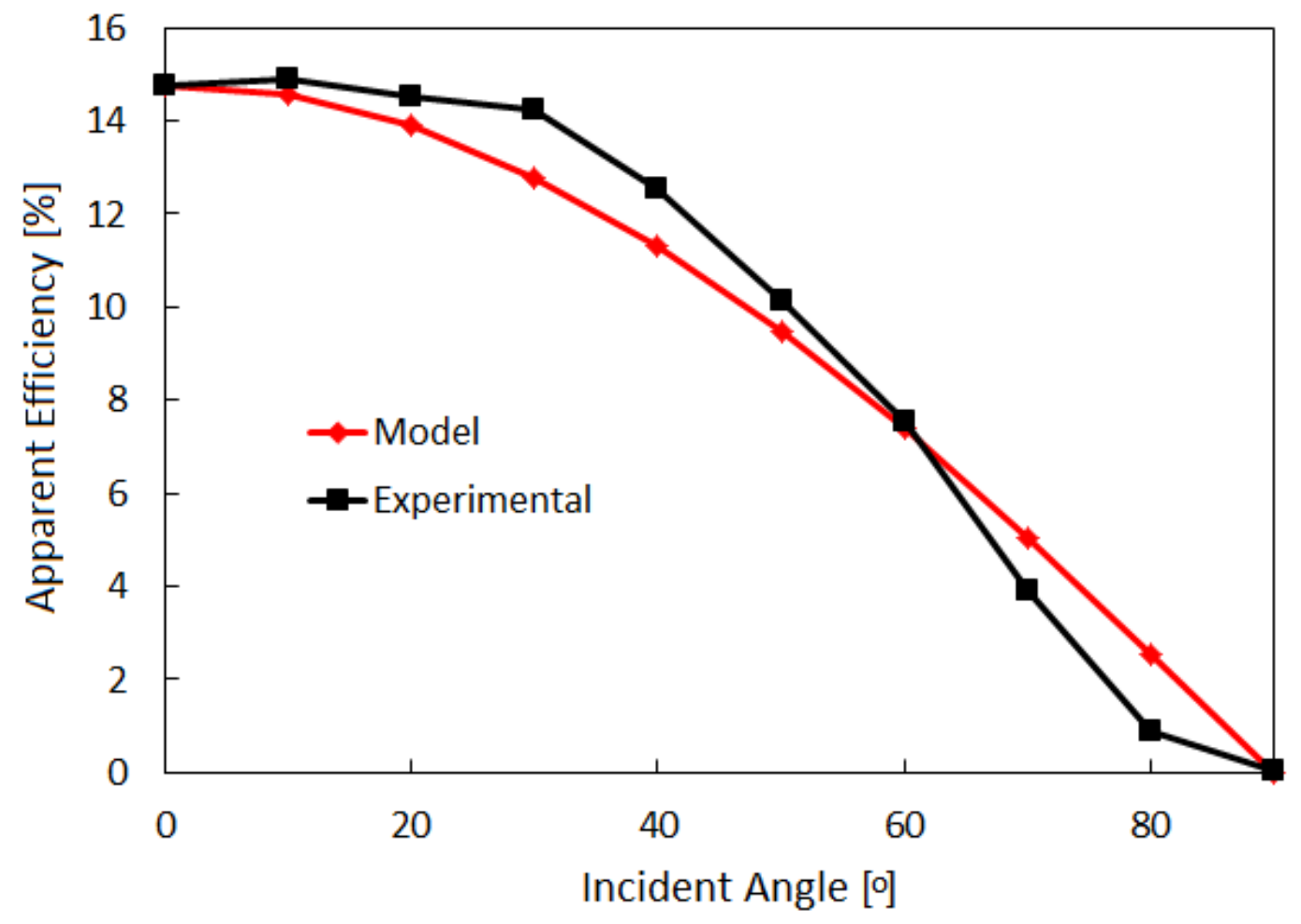

Figure 5: Angle-resolved apparent efficiency measurement as function of the incident angle in one axis in comparison with the expected apparent efficiency decreasing with cosine to the angle. Experimental data for the RIE-textured mono-crystalline Si solar cell are shown. 

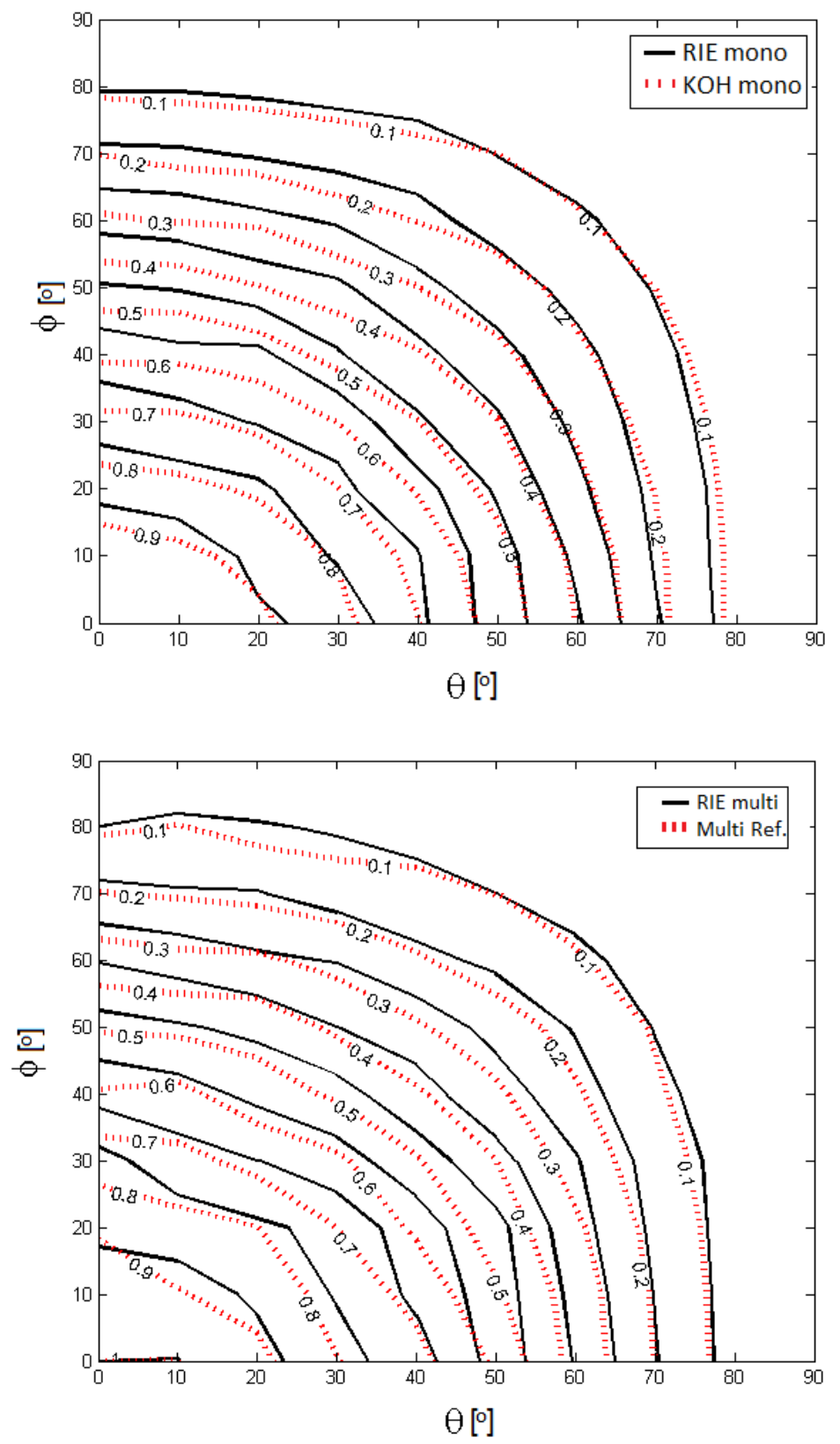

Figure 6: Angle-resolved electrical power output normalized to the power output at $(0,0)$ for the RIE-textured and conventionally textured mono- (top) and multi-crystalline (bottom) Si cell, respectively. 


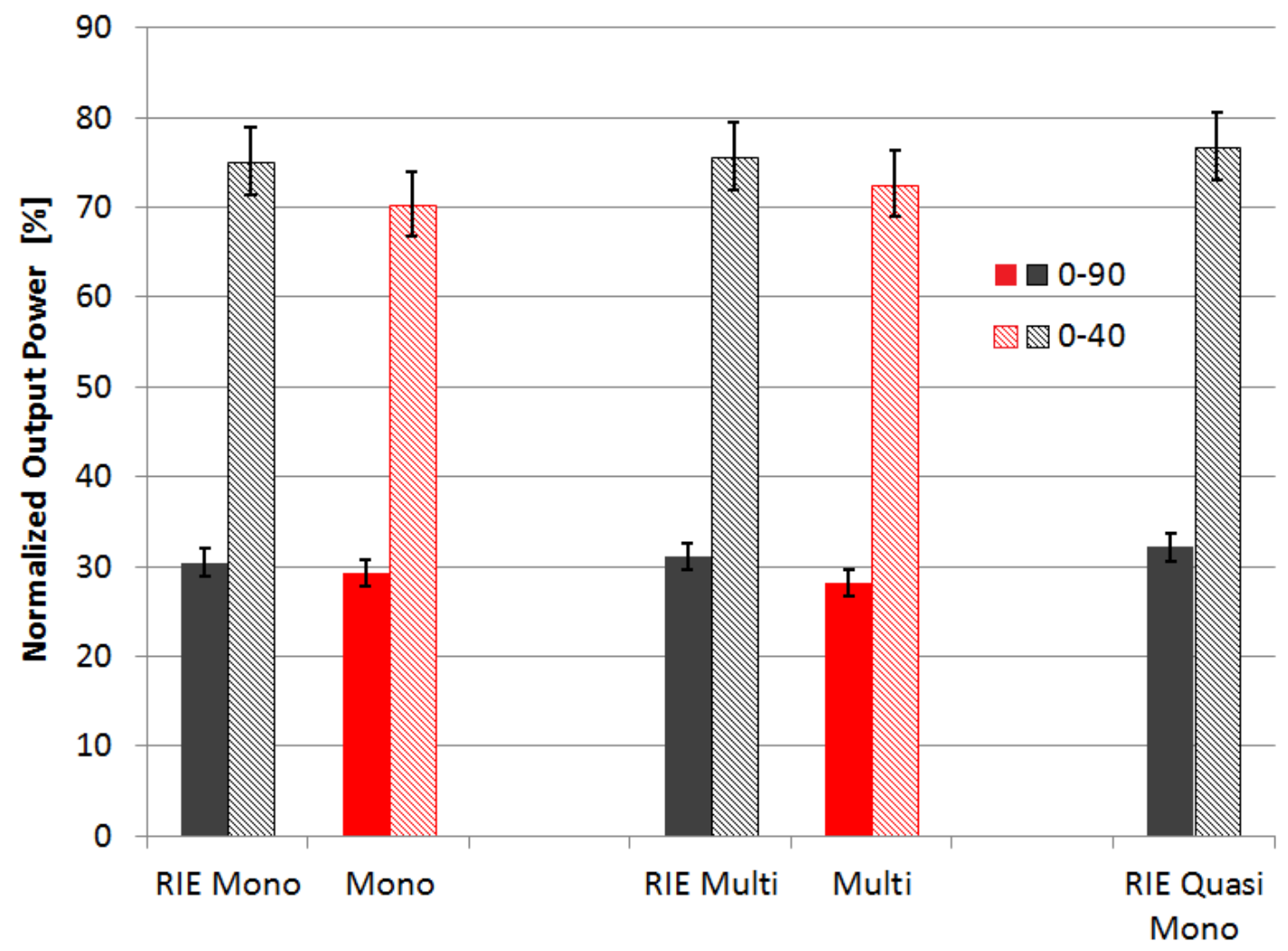

Figure 7: Average normalized electrical power output in the range $0-90^{\circ}$ and $0-40^{\circ}$, respectively, relative to the power output at normal incidence for conventionally and RIE-textured mono, multi and quasi-mono-crystalline Si cells, respectively. 